ESJ Natural/Life/Medical Sciences

\title{
Scientist As Parrhesiastes
}

\author{
Francesco Scotognella
}

Dipartimento di Fisica, Politecnico di Milano, Milano, Italy

Doi:10.19044/esj.2021.v17n25p1

Submitted: 30 March 2021

Accepted: 10 July 2021

Published: 31 July 2021
Copyright 2021 Author(s)

Under Creative Commons BY-NC-ND 4.0 OPEN ACCESS

Cite As:

Scotognella F. (2021). Scientist As Parrhesiastes. European Scientific Journal, ESJ, 17(25), 1.

https://doi.org/10.19044/esj.2021.v17n25p1

\section{Abstract}

The scientific community of the XX and XXI centuries is a very large companionship, very fragmented and spread all over the world. Moreover, the status of the scientist, which in most cases is a member of the States' apparati, is significantly different concerning the one of the scientists up to the First World War.

The concepts of the scientific revolution of Thomas Kuhn and the scientific anarchy of Paul Feyerabend should be reconsidered in this contest. In particular, the anarchist modus operandi should be shifted from the scientific method, which has become significantly standardized with protocols, to the sociology of the scientific community. Pluralism of the scientific method is possible, but anarchy in the relationships among scientists emerges as more important. The scientist is in many cases a parrhesiastes, a person that says the truth even when he is going to pay because of that, that defends the developed theory or model, by respecting the protocols established in the scientific community. On the other side, each scientist should be a patient beholder that accepts the more solid, and intersubjectively recognized, theories of other scientists.

Keywords: Scientific Community, Parrhesia, Anarchy, Paul K. Feyerabend

\section{Introduction}

The scientific community has increased a lot in terms of the number of members in the last decades. For example, in Italy the number of faculties in 
100 years is 30 times larger (Figure 1) (Serie Storiche, n.d.). In the United States, the number of faculties in 1970 is 474000 (of which 369000 full-time), while in 2017 the number of faculties is 1543569 (of which 821168 full-time) (Digest of Education Statistics, 2018, n.d.). According to the UNESCO Science Report, in 2013 there were 7.8 million full-time equivalent researchers with a growth of 21\% since 2007 (https://plus.google.com/+UNESCO, 2015).
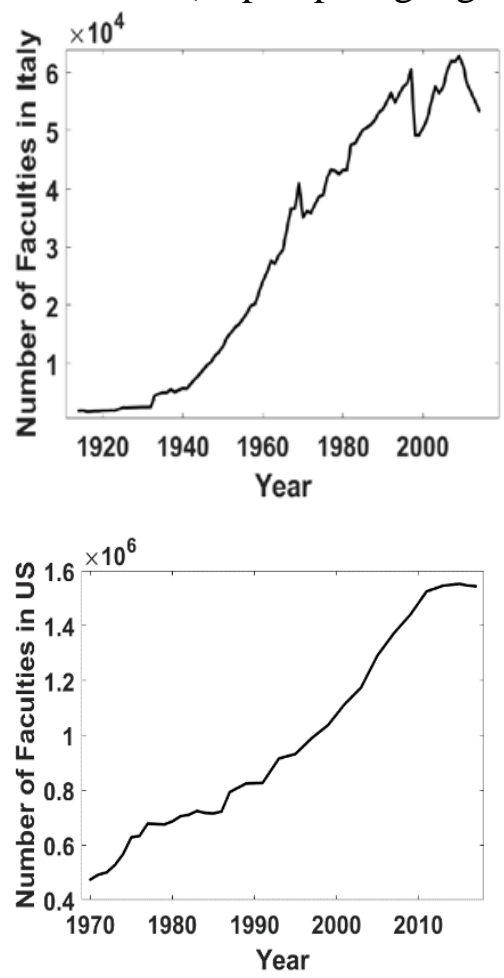

Figure 1. Number of faculties in Italy (Serie Storiche, n.d.) (top) and United States (Digest of Education Statistics, 2018, n.d.) (bottom)

It is well established that the number of publications has enormously increased in the last years. We report three simple examples to highlight this aspect. By looking for publications with the query "graphene" we can find 345 publications in 2006 and 24055 publications in 2020 (source Scopus.com (Scopus - Document Search, n.d.)). With the query "genom*" (the asterisk wildcard replaces multiple characters in a word) we can find 258 publications in 1970 and 70626 publications in 2020 (source Scopus.com (Scopus Document Search, n.d.)). With the query "COVID-19 OR SARS-CoV-2" we can find 88030 publications in 2020 (source Scopus.com (Scopus - Document Search, n.d.)).

In this context, it is difficult to think about a "thought collective" as mentioned by Fleck in Genesis and development of a scientific fact (Fleck et 
al., 2008). A thought collective can be described as a collective of scientists that share common concepts and common practices. Nowadays, the factions in a scientific community are transversal among countries and it is debatable that, for a specific discipline or topic, such a collective of scientists could exist.

Moreover, the vast communities start to have strict protocols, especially in experiments. Since there are so many scientists that work at the same time on a certain topic, it is very difficult to observe a "paradigm shift" (Kuhn), even when such a shift is occurring, considering the huge amount of incremental steps achieved by scientists all over the world.

In this work, we give some examples of scientists that, without an established authority, could contribute significantly in their field behaving as parrhesiastes. According to Michel Foucault, "the parrhesiastes is someone who takes a risk" and is "someone who says everything he has in mind: he does not hide anything, but opens his heart and mind completely to other people through his discourse" (Discourse and Truth, n.d.). Translated to the scientific community the scientist that is a parrhesiastes is not afraid to challenge the most authoritative scientists in the field because they have a more solid theory or model to explain something. We describe briefly, and not exhaustively, some examples of topics of a dispute or of a discovery highlighting the fact the scientist exposed his own model or theory without the fear of being delegitimized by a more authoritative scientist. In the text, we will first report the three examples of disputes between the authoritative scientists and scientist parrhesiastes. In these disputes, we will compare two scientific theories and, for this reason, we will briefly outline our approach that takes into account the notion of incommensurability of scientific theories, as introduced by Thomas Kuhn and Paul Feyerabend. We will then describe the scientific society as an anarchic society in which the members, irrespective of their authority within the society, can contribute with a solid theory or model that will become the most efficient problem-solver for a specific topic. In doing so, we will compare this picture with the pluralistic methodology developed in the masterpiece Against Method of Paul Feyerabend.

\section{Main Text}

\section{Examples of parrhesiastes}

We report three examples of disputes between two scientists (we focussed on physics and chemistry), in which, in a simplified picture, the first scientist is among the most authoritative scientists in a field and the second scientist is the parrhesiastes.

Einstein and Lemaitre: In 1927 Lemaître published a paper that is the first report of the expansion of the universe (Lemaître, 1927). Initially, Einstein, together with contemporary scientists, refuses the theory of Lemaître. In particular, in 1927 Einstein "rejected the notion of an expanding 
Universe as an abomination” (Mitton, 2020; Ostriker \& Mitton, 2013). In 1931, Einstein eventually agreed with the theory proposed by Lemaître (Mitton, 2020). In October 2018, via an electronic vote a "resolution to recommend renaming the Hubble law as the Hubble-Lemaître law has been accepted" (International Astronomical Union | IAU, n.d.).

Heeger and Bässler: Alan J. Heeger is Nobel Prize laureate in Chemistry (2000) develops, together with Su and Schrieffer, a model in which conjugated polymers, macromolecules with backbones made of alternating single and double carbon-carbon bonds, behave like metals, with a conductivity that is inversely proportional to the temperature (Heeger et al., 1988; Su et al., 1979). Years later, Heinz Bässler published a paper in which he describes the conduction in conjugated polymers as characterized by electron-hole pairs (excitons) (Bässler, 1993). The model of Bässler is successful in describing experimental evidence and such model significantly invalidates the model of Heeger, who is among the most authoritative scientists in the field of physics of organic materials.

Pauling and Shechtman: Dan Shechtman has studied alloys and has discovered the icosahedral phase. The new crystallographic phase opens the field of quasicrystals (Shechtman et al., 1984). Shechtman publishes his paper encountering the hostility of many scientists, for example Linus Pauling, Nobel Prize laureate in chemistry and peace. Pauling does not believe in quasicrystals and ridicules the work of Shechtman ('CORRECTED-UPDATE 3-Ridiculed Crystal Work Wins Nobel for Israeli', 2011). Years after his discovery, Dan Shechtman is awarded the Nobel Prize in chemistry (2011).

Since in this work the comparison between different theories is considered, it is very important to discuss the notion of incommensurability in scientific theories. Oberheim in 2004 masterfully reports on the historical origins of incommensurability: Kuhn has been influenced by Fleck, Polanyi and Köhler, while Feyerabend has been mainly influenced by Duhem (Oberheim, 2005). Thomas Kuhn introduces the notion of incommensurability in 1962 in The Structure of Scientific Revolutions (Kuhn, 1996). Feyerabend reports on the notion of incommensurability in 1962 in the work Explanation, Reduction and Empiricism (P. K. Feyerabend, 1962), even if Feyerabend started to elaborate the notion of incommensurability more than a decade earlier (Oberheim, 2005). As clearly summarized by Oberheim:

The idea is that in the course of scientific advance, when fundamental theories change, meanings change, which can result in a new conception of the nature of reality" (Oberheim, 2005).

A careful analysis on the incommensurability between the theories presented in this work, as for example between the theory of Einstein and the theory of Lemaitre on the expansion of the universe, is very interesting, but is beyond the scope of this work. Herein, we compare two different theories, or 
models, and this is methodologically possible both for Kuhn and Feyerabend that state that a comparison between theories, even when they are incommensurable, is possible (Oberheim \& Hoyningen-Huene, 2018). Following Kuhn, it is possible to evaluate which theory is the best problemsolver. For example, the theory of Lemaître better predicts the expansion of the universe with respect to the theory of Einstein. Following Feyerabend, it is possible to stage an experimentuum crucis to validate one of the competing theories. For example, with X-ray diffraction on some alloys we can corroborate the model of quasicrystals (Shechtman et al., 1984).

Another interesting point that could be analysed in further works is the possible efficacy of the best problem-solvers among the scientific theories in addressing societal pressing problems. This analysis could challenge the one of Feyerabend who in The Tyranny of Science (P. Feyerabend \& Oberheim, 2011) strongly criticizes the success of science. For Feyerabend, scientists prefer to focus on generalizations neglecting the details that are evident in the daily experience.

\section{The anarchy in the scientific community}

These three examples underline that the scientist is going to present the developed model or theory as a parrhesiastes and the scientific community (or at least the majority of such community) is composed of patient beholders that are willing to understand the validity of the model or theory. Thus, the scientific society can be described as an anarchic society, in which the concentration of power of any authority, with established knowledge in any topic, is only apparent and temporary since any member can say something more solid concerning such topic. Such members of the scientific society are parrhesiastes when taking the risk of saying the truth, especially when the developed theory or model competes with the one of a scientific authority. However, after several discussions and after significant (crucial) experiments, the scientific society will recognize the best problem-solver among the competing theories. We would like to compare this picture with the one of Feyerabend (especially Feyerabend's thought in Against Method).

\section{Objections to Feyerabend}

The pluralistic methodology of Feyerabend authorizes any methods, even unconventional methods. Feyerabend is against methodological monism, and he suggests methodological pluralism. In this study we do not want to argue with this internationally recognized and fascinating methodology, as recently reported by Brown and Kidd (Brown \& Kidd, 2016) and in the special issue of Studies in History and Philosophy of Science Part A entitled Reappraising Feyerabend. In such a special issue Brown stresses the metaphysics of science of the late Feyerabend that emphasizes the absolute 
abundance of the world and the ineffability of Being (Brown, 2016). Furthermore, it has been masterfully reported by Shaw in Ref. (Shaw, 2017) that methodological pluralism can be described as "methodological opportunism". With the clear risk of an oversimplification, we underline the cumbersome employment of such methodological opportunism in the contemporary scientific community. To be clearer, we just want to cite the words of Luca Guzzardi:

And it is certainly not the case that "anything goes." Something "goes" only if it can be integrated within the various elements that form a given dictionary (Guzzardi, 2018)

Where the "dictionary" relates to the "scientist's dictionary" of Enrico Bellone (Bellone, 1980). Here, we aim to recall the scientist's dictionary that includes some rigorous instruments such as theoretical frameworks, experimental procedures and protocols. Such instruments should be followed to make the discovery reliable for the community.

On the other hand, Feyerabend uses the term Dadaism to rule the political implication of the use of the term anarchy. Anyway, for Feyerabend Dadaism or anarchy relates to a scientific pluralistic environment in which "anything goes". What we would like to stress is that pluralism is not strictly anarchism. In principle, there could be a societal organization, with an actual exercise of power, that is pluralist (e.g. a complex democracy with an extended system of checks and balances).

Taking into account these considerations, we would like to state that the scientific society is inherently an anarchic society: Anyone can develop a theory or model that works or an experimentum crucis that can be built or performed by anyone that has the proper instruments.

Why are we talking about anarchy and not about democracy? One can argue that, like in a democracy, the scientist/parrhesiastes is looking for a consensus and, if successful, the scientist will gain a larger consensus concerning one of the authorities. The scientist does not look for a consensus among the majority of the community. For example, Perelman publishes the solution of the Poincarè conjecture on a proper medium (the repository arXiv) (Perelman, 2002, 2003a, 2003b) without the consensus of other mathematicians in the field. Years later, the solution of Perelman has been widely (intersubjectively) recognized.

\section{Conclusion}

In this work three examples have been reported in which a scientist behaves as a parrhesiastes, which exposes a solid theoretical framework or interpretation of data that go against the knowledge of the scientific community including the most authoritative standards. Such a community, that also includes careful and patient listeners, eventually accepts the more 
solid and reliable model of the parrhesiastes. Inductively, an anarchic society, without the need for consensus and authoritative positions, can be considered as an interesting description of the scientific community.

\section{References:}

1. Bässler, H. (1993). Charge Transport in Disordered Organic Photoconductors a Monte Carlo Simulation Study. Physica Status Solidi (b), 175(1), 15-56. https://doi.org/10.1002/pssb.2221750102

2. Bellone, E. (1980). A world on paper: Studies on the second scientific revolution. MIT Press.

3. Brown, M. J. (2016). The abundant world: Paul Feyerabend's metaphysics of science. Studies in History and Philosophy of Science Part A, 57, 142-154. https://doi.org/10.1016/j.shpsa.2015.11.015

4. Brown, M. J., \& Kidd, I. J. (2016). Introduction: Reappraising Paul Feyerabend. Studies in History and Philosophy of Science Part A, 57, 1-8. https://doi.org/10.1016/j.shpsa.2015.11.003

5. CORRECTED-UPDATE 3-Ridiculed crystal work wins Nobel for Israeli. (2011, October 5). Reuters.

https://www.reuters.com/article/nobel-chemistryidUSL5E7L51U620111005

6. Digest of Education Statistics, 2018. (n.d.). National Center for Education Statistics. Retrieved 25 May 2020, from https://nces.ed.gov/programs/digest/d18/tables/dt18_315.10.asp

7. Discourse and Truth: The Problematization of Parrhesia: 6 lectures given by Michel Foucault at the University of California at Berkeley, Oct-Nov. 1983. (n.d.). Michel Foucault, Info. Retrieved 8 September 2020, from https://foucault.info/parrhesia/

8. Feyerabend, P. K. (1962). Explanation, reduction, and empiricism. http://conservancy.umn.edu/handle/11299/184633

9. Feyerabend, P., \& Oberheim, E. (2011). Tyranny of science. Polity Press.

10. Fleck, L., Trenn, T. J., Merton, R. K., \& Bradley, F. (2008). Genesis and development of a scientific fact (Repr. 11. Aufl). Univ. of Chicago Press.

11. Guzzardi, L. (2018). The Logic That Governs Each Step of Scientific Research. Isis, 109(1), 105-108. https://doi.org/10.1086/697110

12. Heeger, A. J., Kivelson, S., Schrieffer, J. R., \& Su, W.-P. (1988). Solitons in conducting polymers. Reviews of Modern Physics, 60(3), 781-850. https://doi.org/10.1103/RevModPhys.60.781

13. https://plus.google.com/+UNESCO. (2015, November 4). Facts and figures: Human resources. UNESCO.

https://en.unesco.org/node/252277 
14. International Astronomical Union | IAU. (n.d.). Retrieved 10 September 2020, from https://www.iau.org/news/pressreleases/detail/iau1812/?lang

15. Kuhn, T. S. (1996). The structure of scientific revolutions (3rd ed). University of Chicago Press.

16. Lemaître, G. (1927). Un Univers homogène de masse constante et de rayon croissant rendant compte de la vitesse radiale des nébuleuses extra-galactiques. Annales de La Société Scientifique de Bruxelles, 47, 49-59.

17. Mitton, S. A. (2020). Georges Lemaitre and the foundations of Big Bang cosmology. The Antiquarian Astronomer, 14, 2-20. https://arxiv.org/abs/2007.09459.

18. Oberheim, E. (2005). On the historical origins of the contemporary notion of incommensurability: Paul Feyerabend's assault on conceptual conservativism. Studies in History and Philosophy of Science Part A, 36(2), 363-390.

https://doi.org/10.1016/j.shpsa.2005.04.003

19. Oberheim, E., \& Hoyningen-Huene, P. (2018). The Incommensurability of Scientific Theories. In E. N. Zalta (Ed.), The Stanford Encyclopedia of Philosophy (Fall 2018). Metaphysics Research Lab, Stanford University. https://plato.stanford.edu/archives/fall2018/entries/incommensurabilit $\mathrm{y} /$

20. Ostriker, J. P., \& Mitton, S. (2013). Heart of darkness: Unraveling the mysteries of the invisible universe. Princeton University Press.

21. Perelman, G. (2002). The entropy formula for the Ricci flow and its geometric applications. ArXiv:Math/0211159. http://arxiv.org/abs/math/0211159

22. Perelman, G. (2003a). Ricci flow with surgery on three-manifolds. ArXiv:Math/0303109. http://arxiv.org/abs/math/0303109

23. Perelman, G. (2003b). Finite extinction time for the solutions to the Ricci flow on certain three-manifolds. ArXiv:Math/0307245. http://arxiv.org/abs/math/0307245

24. Scopus-Document search. (n.d.). Retrieved 15 February 2021, from https://www.scopus.com/search/form.uri?display=basic\#basic

25. Serie Storiche. (n.d.). Retrieved 24 May 2020, from http://seriestoriche.istat.it/index.php?id=1\&no_cache=1\&tx_usercent o_centofe\%5Bcategoria\%5D=7\&tx_usercento_centofe\%5Baction\%5 $\mathrm{D}=$ show\&tx_usercento_centofe\%5Bcontroller\%5D=Categoria\&cHas $\mathrm{h}=1 \mathrm{~b} 020 \mathrm{e} 5419 \mathrm{ca} 607971010 \mathrm{a} 98271 \mathrm{e} 3209$ 
26. Shaw, J. (2017). Was Feyerabend an anarchist? The structure(s) of 'anything goes'. Studies in History and Philosophy of Science Part A, 64, 11-21. https://doi.org/10.1016/j.shpsa.2017.06.002

27. Shechtman, D., Blech, I., Gratias, D., \& Cahn, J. W. (1984). Metallic Phase with Long-Range Orientational Order and No Translational Symmetry. Physical Review Letters, 53(20), 1951-1953. https://doi.org/10.1103/PhysRevLett.53.1951

28. Su, W. P., Schrieffer, J. R., \& Heeger, A. J. (1979). Solitons in Polyacetylene. Physical Review Letters, 42(25), 1698-1701. https://doi.org/10.1103/PhysRevLett.42.1698 